\title{
Medical Students' Epistemological Beliefs: Implications for Curriculum
}

\author{
Dwight Assenheimer1, Katherine Knox ${ }^{2}$, Vishna Devi Nadarajah ${ }^{3}$, Craig Zimitat ${ }^{1,4}$ \\ 'School of Medicine, Faculty of Health, University of Tasmania, Hobart, 'Department of Psychology, Griffith University, Brisbane, Australia, \\ ${ }^{3}$ International Medical University, Kuala Lumpur, Malaysia, ${ }^{4}$ Centre for Learning and Teaching, Curtin University, Perth, Western Australia
}

\begin{abstract}
Background: Epistemological beliefs have a pervasive influence on learning and practice. Understanding these beliefs and how they develop, could play an important role in medical student training and shape later clinical practice. Methods: The epistemological beliefs of first-year medical students from an Australian and Malaysian university were explored using a domain-specific instrument. Results: There were significant differences between the disciplinary epistemological beliefs of Australian and Malaysian medical students across many items, and two specific factors (Certainty of Knowledge and Justification for Knowing). Discussion: These findings have potential implications for teaching in biomedical disciplines and adaptation of Western curriculum innovations in Eastern educational contexts. Further work is needed to confirm and understand any epistemological differences and subsequent implications for learning and teaching in medicine.
\end{abstract}

Keywords: Culture, curriculum, epistemology, knowledge beliefs, problem-based learning

\section{Background}

Researchers in education have developed deeper understandings about student learning in medicine over the last two decades. Studies have examined learning strategies, teaching and assessment activities and learning outcomes, and the relationships between these in many different disciplines, including medicine. ${ }^{[1-3]}$ Little is known however about medical students' epistemological beliefs, i.e., their beliefs about knowledge per se. Roex and Degryse ${ }^{[4]}$ and Evans et al. ${ }^{[5]}$ suggest that understanding these beliefs may play an important role in medical education and later practice.

Epistemological beliefs evolve as individuals move through the education system. Research with US college students ${ }^{[6,7]}$ indicates that students follow a common trajectory in

\begin{tabular}{|l|l|}
\hline \multicolumn{2}{|c|}{ Access this article online } \\
\hline Quick Response Code: & Website: \\
& www.educationforhealth.net \\
\cline { 2 - 2 } & \\
& \\
\hline
\end{tabular}

\section{Address for correspondence:}

Professor. Craig Zimitat, School of Medicine, Faculty of Health, University of Tasmania, Hobart, Australia.

E-mail: craig.zimitat@utas.edu.au developing increasingly complex beliefs throughout their formal education. In contrast to this staged, uni-dimensional model, others ${ }^{[8,9]}$ have proposed a model where epistemological beliefs have multiple elements that develop independently over time. There are several validated epistemological beliefs instruments in use, ${ }^{[10-12]}$ though there are differences among them in focus and structure. There is common empirical evidence for four different dimensions of beliefs: Beliefs about the Source of Knowledge (SK), Justification for Knowing (JK), Certainty of Knowledge (CK) and Attainability of Truth (AT), and the majority of questionnaire instruments examining epistemological beliefs are inclusive of this multidimensional model. ${ }^{[13]}$

While there is evidence for general epistemological beliefs, there is also a growing body of work exploring epistemological beliefs in academic disciplines among Western students of science, psychology, history and mathematics ${ }^{[8,14]}$ and Malaysian students of the social and physical sciences. ${ }^{[15]}$ It appears that domain specific beliefs exist within a framework

This is an open access article distributed under the terms of the Creative Commons Attribution-NonCommercial-ShareAlike 3.0 License, which allows others to remix, tweak, and build upon the work non-commercially, as long as the author is credited and the new creations are licensed under the identical terms.

For reprints contact: reprints@ medknow.com

How to cite this article: Assenheimer D, Knox K, Nadarajah VD, Zimitat C. Medical students' epistemological beliefs: Implications for curriculum. Educ Health 2016;29:107-12. 
of general beliefs, with apparent inconsistencies between some of these general and disciplinary beliefs. ${ }^{[16]}$ Some educational strategies (e.g., problem-based learning, PBL) are associated with the development of sophisticated epistemological beliefs. ${ }^{[14,17-19]}$ Culture also plays an important role in learning and shaping epistemological beliefs, ${ }^{[20,21]}$ although it is still unclear what differences in epistemological beliefs or their development exist between Asian and Western students.

Epistemological beliefs play a central, but poorly understood, role in the overall teaching and learning enterprise. Students take epistemological cues from teachers and their educational strategies and at this level, teachers' epistemological beliefs impact upon their teaching methods, ${ }^{[19]}$ which in turn affects student attitudes and learning outcomes. At the level of the learner, students' epistemological beliefs are related to their motivation for learning, learning approaches, cognitive strategies and academic achievement. ${ }^{[22]}$ Ismail et al.'s studies with Malaysian students ${ }^{[15]}$ provide evidence that students' epistemological beliefs correlate strongly with their conceptions of learning and deep/surface approaches to learning. Student's epistemological beliefs influence how they manage, weigh information and generate meaning from that information..$^{[8,23]}$ The relative consideration of empirical evidence (e.g., clinical tests) and subjective evidence (patient narrative) has potential implications for clinical reasoning, practice and the nature of patient-care.

Undergraduate medical students around the world are primarily selected on the basis of previous academic success; and many students entering medicine have a strong science background. On that basis, it might be expected that many first-year undergraduate medical students might have similar epistemological beliefs. However, given potential effects of learning environments and culture, differences may exist between students from Eastern and Western educational systems ${ }^{[24]}$ with unknown impacts upon teaching and learning. In this preliminary study, we explored the epistemological beliefs of first-year medical students, and compared two cohorts from an Australian and a Malaysian university.

\section{Methods}

Epistemological beliefs of first-year medical students about medical knowledge were examined using the Discipline Focused Epistemological Beliefs (DFEB) questionnaire, ${ }^{[8,12]}$ distributed in paper format at a lecture, completed voluntarily and returned three days later. The DFEB is an 18-item, self-report measure of epistemological beliefs situated and validated in the science disciplines. It was adapted for use with medical students, by insertion of the term medical/doctor where relevant, and confirmed by Malaysian colleagues to be appropriate related to their cultural and academic context. The DFEB consists of four dimensions of personal epistemology:
Certainty of Knowledge (CK, eight items), Justification for Knowing (JK, four items), Source of Knowledge (SK, four items) and Attainability of Truth (AT, two items). Individual items were rated on a Likert scale with numerical scores ( $1=$ strongly disagree to $5=$ strongly agree). Lower scores $(<2)$ indicated more flexible, relative, 'grey', sophisticated epistemological beliefs; while higher scores $(>3)$ indicated firmer, 'black and white', unsophisticated epistemological beliefs. The $\mathrm{DFEB}^{[8]}$ does not use open-ended questions. The mean and standard deviations for individual items and each factor were compared between the Australian and Malaysian student groups using independent $t$-tests, adjusted for inequality of variances as necessary. This study was approved by the Human Research Ethics Committee (Tasmania) Network.

\section{Results}

Completed surveys were returned by 132/230 (69\%) Australian medical students and 97/160 (61\%) Malaysian medical students. The age and gender profile of the Australian and Malaysian cohorts were similar. Likert responses were converted to numerical scores for statistical analysis ( $1=$ strongly disagree to $5=$ strongly agree). The groups differed significantly on 13 of 18 individual items of the DFEB [means and $t$-test results are summarised in Table 1]. First-year Australian medical students scored significantly lower $(P<0.05)$ than Malaysian students on 10 items, while Malaysian students scored significantly lower than Australian students on only three items (Q1, 7, 12). Most of the items with the greatest differences in scores and where there were significant differences in scores were associated with $\mathrm{CK}$ and JK. The largest difference in means was between CK questions (.401) and JK questions (.428).

Regarding the four factor scores, Australian medical students scored significantly lower than the Malaysian students on $\mathrm{CK}[\mathrm{t}(227)=-3.31, P<0.001]$ and JK $[\mathrm{t}(227)=-3.30$, $P<0.001]$ indicating they hold more sophisticated or flexible beliefs across those domains [Table 1]. Across the whole sample $(n=229$ ) subscale reliabilities were poor (JK, $\alpha=0.390$; AT, $\alpha=0.136$ ) to acceptable (CK, $\alpha=0.645$; SK, $\alpha=0.502)$. Removing Q12 would increase the JK $\alpha$ score to 0.61 . Removing items made little difference to other reliability scores. The internal reliability estimates for factors $\mathrm{CK}$ and SK in the Malaysian group were numerically higher than for Australian group, while that for AT was much lower.

\section{Discussion}

This is the first study of medical students' epistemological beliefs, conducted across cultures. This preliminary study reveals three significant findings: First, Australian medical students scored similarly to American science students on the DFEB ${ }^{[8]}$ second, there were significant differences in some epistemological beliefs between Australian and Malaysian 


\begin{tabular}{|c|c|c|c|c|c|c|}
\hline \multirow[t]{2}{*}{ Scales and items } & \multicolumn{2}{|c|}{$\begin{array}{l}\text { Australian } \\
\text { students }(n=132)\end{array}$} & \multicolumn{2}{|c|}{$\begin{array}{c}\text { Malaysian } \\
\text { students }(n=97)\end{array}$} & \multirow[t]{2}{*}{$t$-test } & \multirow[t]{2}{*}{$P$} \\
\hline & $\alpha$ & Mean, SD & $\alpha$ & Mean, SD & & \\
\hline Factor 1. Certainty/simplicity of knowledge (8 items) & 62 & $2.02,0.43$ & 69 & $2.15,0.63$ & 3.03 & $<0.001^{*}$ \\
\hline Q1. Answers to questions in medicine do not change as experts gather more information & & $2.23,0.98$ & & $1.78,0.93$ & 3.55 & $<0.001^{*}$ \\
\hline Q2. All experts in medicine understand the discipline in the same way & & $2.06,0.84$ & & $2.40,0.99$ & 2.79 & $0.006^{*}$ \\
\hline Q3. Truth is unchanging in medicine & & $2.15,1.07$ & & $2.63,1.24$ & 3.03 & $0.003^{*}$ \\
\hline Q4. In medicine, most problems have only one right answer & & $1.69,0.64$ & & $1.86,0.88$ & 1.58 & 0.116 \\
\hline Q5. Principles in medicine are unchanging & & $1.95,0.86$ & & $2.67,1.34$ & 4.65 & $<0.001^{*}$ \\
\hline $\begin{array}{l}\text { Q6. All professors of medicine would probably come up with the same answers to questions in this } \\
\text { field }\end{array}$ & & $1.99,0.80$ & & $2.35,0.94$ & 3.05 & $0.003^{*}$ \\
\hline Q7. In medicine, it is not good to question the ideas presented & & $1.82,0.64$ & & $1.58,0.58$ & 2.93 & $0.003^{*}$ \\
\hline Q8. Most of what is true in medicine is already known & & $2.30,0.87$ & & $2.74,0.99$ & 3.60 & $<0.001^{*}$ \\
\hline Factor 2. Justification for knowing: Personal (4 items) & 0.43 & $2.75,0.59$ & 0.39 & $3.01,0.64$ & 5.55 & $<0.001^{*}$ \\
\hline Q9. First-hand experience is the best way of knowing something in medicine & & $3.11,0.91$ & & $3.36,1.00$ & 2.00 & $<0.046^{*}$ \\
\hline $\begin{array}{l}\text { Q10. I am more likely to accept the ideas of medical doctors with firsthand experience than the ideas } \\
\text { of medical researchers }\end{array}$ & & $2.43,0.85$ & & $2.90,1.04$ & 3.73 & $<0.001^{*}$ \\
\hline Q11. Correct answers in medicine are more a matter of opinion than fact & & $2.28,0.78$ & & $2.94,1.15$ & 4.70 & $<0.001^{*}$ \\
\hline Q12. There is really no way to determine whether someone has the right answer in medicine & & $3.19,0.95$ & & $2.86,1.10$ & 2.40 & $0.017^{\star}$ \\
\hline Factor 3. Source of knowledge: Authority (4 items) & 0.41 & $2.95,0.69$ & 0.56 & $3.07,0.82$ & 1.44 & 0.163 \\
\hline $\begin{array}{l}\text { Q13. Sometimes you just have to accept answers from the experts in medicine, even if you don't } \\
\text { understand them }\end{array}$ & & $2.48,0.83$ & & $2.86,0.99$ & 3.09 & $0.002^{*}$ \\
\hline Q14. If you read something in a medical textbook, you can be sure it's true & & $2.78,0.83$ & & $2.69,0.85$ & 0.80 & 0.424 \\
\hline Q15. If my personal experience conflicts with ideas in medical textbooks, the book is probably right & & $3.55,0.75$ & & $3.56,0.83$ & 0.035 & 0.972 \\
\hline Q16. I am most confident that I know something when I know what the experts think & & $3.06,0.79$ & & $3.19,0.90$ & 1.09 & 0.276 \\
\hline Factor 4. Attainability of truth (2 items) & 0.31 & $3.60,0.50$ & 0.02 & $3.76,0.55$ & 1.78 & 0.072 \\
\hline Q17. Experts in medicine ultimately get to the truth & & $2.92,0.99$ & & $4.18,0.68$ & 3.12 & $0.002^{*}$ \\
\hline Q18. If medical researchers try hard enough, they can find the answers to almost anything & & $4.30,0.67$ & & $3.34,1.06$ & 1.33 & 0.185 \\
\hline
\end{tabular}

${ }^{*}$ Statistically significant $P<0.05 . \mathrm{SD}=$ Standard deviation

first-year medical student. And third, the data support the notion of multiple dimensions of disciplinary epistemological beliefs amongst first-year medical students.

Disciplinary epistemological beliefs have largely been explored with psychology and science students in the United States. There are very limited data available for comparison, however Australian students' mean scores for CK, JK, SK and AT were very similar to those of first-year American science students (Hofer, 1997) indicating that they held similar epistemological beliefs. This study also confirms the pattern of higher factor scores for Asian students compared with Western students..$^{[20,21]}$

There appear to be differences in the firmness of epistemological beliefs held by Australian and Malaysian students. The magnitude of differences of item means was modest $(<0.50)$, hence the two groups are at the same end of the spectrum which may reflect similarities in their academic background on entry into medicine. Cultural bias in the DFEB cannot be excluded as contributing to the differences, however the instrument was considered by Malaysian colleagues to be appropriate to their cultural and academic context. Additionally, while the age and gender profiles and response rates of the two cohorts were similar, data could not be collected for ethical reasons. The role of gender in epistemology is inconclusive, ${ }^{[8]}$ [out of order numerically] and its contribution to differences in scores can not be assessed or excluded.

First-year Malaysian medical students consistently scored significantly higher than Australian students on many CK and JK items, indicative of stronger beliefs regarding factual accuracy, knowledge being external and held by authoritative sources, and a single common view of knowledge. Malaysian students reported stronger beliefs than Australian students about the static (Q8) and consistent (Q3, Q4) knowledge base underpinning medicine, which may reflect differences in teaching styles or culture. Australian students were less likely than their Malaysian colleagues to "accept" answers from experts (Q13), presumably academic and clinical teaching staff, even if they did not understand the reasoning. This finding is consistent with other beliefs held by Eastern students regarding respect for authority, elders and teachers. ${ }^{[20,21]}$ In this study, both groups of students scored similarly on SK indicating beliefs that answers to many questions were held by authoritative sources. Some of the apparent inconsistency between responses to $\mathrm{CK}$ items is reflected in a student reflection. ${ }^{[25]}$ "Years of experience don't modify the principles [in] 
the engineering book, but in medicine they do". Thus, the examination culture in medical schools may reinforce book as authority, but clinical learning experiences promote the senior clinician as alternate authority.

The DFEB has been used with Science and Psychology students and appears to be suitable for exploring epistemological beliefs in the broader discipline area as much as the sub-disciplines. ${ }^{[22]}$ There do appear to be differences in students' beliefs about knowledge in different sub-disciplines of medicine, e.g., anatomy and biochemistry. ${ }^{[25]}$ In this study, students were enrolled in PBL medical courses where the disciplines are integrated, which potentially limits the visibility of the disciplines in the curriculum and the development of specific beliefs regarding those sub-discipline areas. However, despite an apparent common philosophical base, PBL curricula are implemented in very different ways, ${ }^{[26]}$ hence this assumption may not hold true for all PBL curricula.

The analysis of the whole sample provides some support for the multidimensional model of disciplinary epistemological beliefs amongst medical students. Subscale reliabilities across the whole sample were average (AT, JK) to acceptable (CK, SK), but were lower than those reported by Hofer. ${ }^{[12]}$ This may be partly attributable to the sample size in this study, partly due to the discipline (medicine) of interest compared to those referred to in previous research, or partly due to within-group variability (e.g., age and gender) of the current total sample and differences in education systems. Differences in the internal reliability estimates between the Malaysian and Australian group raise the possibility of an alternative factor structure that would better fit the data in the current samples. As the DFEB was developed and most research undertaken with American college students, this finding provides support for additional epistemological constructs evident in other cultures ${ }^{[20]}$ Further work to understand potential cultural differences will need to be undertaken to explore epistemological beliefs both among Malaysian students and undergraduate medical contexts.

Developing complex epistemological beliefs is a desirable outcome of health professions education because of the potential influence on learning and later professional practice. Chan ${ }^{[20]}$ argues that the nature of epistemological beliefs held by students predicts their conceptions of learning and approaches to study, which have been correlated with learning outcomes. ${ }^{[1]}$ Evans et al.$^{[5]}$ propose that medical graduates with firm beliefs about the certainty of knowledge and justification of knowledge may not be well-suited for the uncertainty of general practice. Labasky ${ }^{[27]}$ reported that absolutist views of knowledge impeded sound clinical decision-making by nurses. Epistemological beliefs can impact upon practice and care. Understanding the epistemological stance of students may enable the tailoring of curriculum strategies and teaching practices to maximise the potential for developing the sophistication of those beliefs, with subsequent impacts on practice. The literature would suggest that inquiry-based or problem-based strategies where students need to make sense of messy information are most powerful. Despite significant changes in medical education over the last two decades, there are few examples of how students' epistemological beliefs are explicitly addressed by new curriculum approaches.

PBL is one of the more recent curriculum innovations in medical education. At the curriculum level, PBL and inquiry-based learning curricula appear to have significant effects on developing epistemological beliefs in the social sciences ${ }^{[19]}$ and would be expected to have the greatest positive effects for Malaysian students. The development of PBL has largely been in Western medical education contexts and its implementation quite variable, ${ }^{[26]}$ so its application without modification in Eastern contexts may not be optimal to achieve this outcome. This is further complicated by potential differences in epistemological beliefs among different ethic Malaysian groups, ${ }^{[15]}$ which was not explored in this study. Large numbers of lectures and poorly designed PBL cases risk reinforcing beliefs rather than challenging them. Ill-structured, open-ended problems that require thinking and re-thinking as uncertainties are resolved or emerge are most likely to bring epistemological beliefs to the surface for challenge. Students' capacity to set their own learning objectives and undertake self-directed learning may also be limited by their epistemological stance when they enter the course, hence they may need greater cognitive scaffolding to prepare them to engage with deeper ways of learning and critical reflection. In the area of assessment, an over-reliance on multiple choice questions may give the impression that there is always one correct answer to questions, reinforcing beliefs regarding the certainty of knowledge which may impact upon all students early in the course, but also have greater impacts on Malaysian than Australian students. These are just several implications of this study for adaptations for PBL medical curricula in Malaysia.

At the classroom level, developing students' epistemological beliefs is essential because of their pervasive influence on motivation, learning approaches and outcomes. Large numbers of lectures within a PBL curriculum may have many perverse effects. Compared with anatomy, teaching in biochemistry and physiology appears to challenge student's epistemological beliefs. ${ }^{[25,28]}$ As a Cornell medical student reflected "they may not know everything about the biochemistry of the body ... but when it comes to the gross anatomy, they know just about all there is to know". ${ }^{[25]}$ They may relate to the different ways in which the disciplines are taught and assessed. Traditional anatomy teaching strategies reinforce undeveloped beliefs about the certainty, justification and source of knowledge. If anatomy was taught and assessed using a more experimental and socio-cultural perspective or integrated with other disciplines, students might appreciate both the well-established and 
contested knowledge bases of the discipline. This approach may challenge their beliefs, promote deeper approaches to learning and better learning outcomes in both the short and longer term.

There are several limitations to this work. First, the impact of gender in this study as confounder cannot be totally excluded. Second, this is a single time-point study, restricted to first year undergraduate medical students in two medical schools. The longitudinal effects of the medical curricula and clinical learning in authentic settings needs to be determined and will require follow up studies on students as they progress through the course. Third, the DFEB has not been validated with senior-year medical students in the clinical years, thus conclusions should be restricted to learning of biomedical sciences in the early years of medical study. Finally, there was no consideration of ethnicity in the Malaysian cohort data; so implications cannot be attributed or associated with specific ethnic groups.

\section{Conclusion}

This study is the first to report on the disciplinary epistemological beliefs of first-year medical students across the Eastern and Western higher education systems. There appear to be significant differences in the disciplinary epistemological beliefs held by students from Australia and Malaysia. Some of these differences may arise in part from different cultural and learning environments in the two countries. These findings have implications for the implementation and adaptation of Western curriculum innovations in Eastern educational environments. Further work is needed to confirm these data through triangulation with gender, academic performance and exploration of perceptions by interview, to examine how medical students' epistemological beliefs evolve and can be developed through specific pedagogical approaches.

\section{Acknowledgement}

We would like to acknowledge the contributions of our students in participating in this research project.

\section{Financial support and sponsorship}

Nil.

\section{Conflicts of interest}

There are no conflicts of interest.

\section{References}

1. Biggs JB, Tang C. Teaching for Quality Learning at University. $3^{\text {rd }}$ ed. London: Open University Press; 2003.

2. Entwistle NJ, Ramsden P. Understanding Student Learning. London: Croom Helm; 1983.
3. Ramsden P, Whelan G, Cooper D. Some phenomena of medical students' diagnostic problem-solving. Med Educ 1989;23:108-17.

4. Roex A, Degryse J. Introducing the concept of epistemological beliefs into medical education: The hot-air-balloon metaphor. Acad Med 2007;82:616-20.

5. Evans L, Trotter DR, Jones BG, Ragain RM, Cook RL, Prabhu FR, et al. Epistemology and uncertainty: A follow-up study with third-year medical students. Fam Med 2012;44:14-21.

6. Perry WG. Forms of Intellectural and Ethical Development in the College Years: A Scheme. New York: Holt, Rinehart and Winston; 1970.

7. Kuhn D, Weinstock M. What is epistemological thinking and why does it matter? In: Hofer BK, Pintrich PR, editors. Personal Epistemology: The Psychological Beliefs about Knowledge and Knowing. Mahwah, NJ: Lawrence Erlbaum Association; 2002.

8. Hofer BK. Dimensionality and disciplinary differences in personal epistemology. Contemp Educ Psychol 2000;25:378-405.

9. Schommer M. Epistemological development and academic performance among secondary schools. J Educ Psychol 1993;85:406-11.

10. Schommer M. Effects of beliefs about the nature of knowledge on comprehension. J Educ Psychol 1990;82:498-504.

11. Schraw G, Bendixen LD, Dunkle ME. Development and evaluation of the epistemic beliefs inventory. In: Hofer BK, Pintrich PR, editors. Personal Epistemology: The Psychology of Belifes about Knowlegde and Knowing. Mahwah, NJ: Lawrence Erlbaum and Association; 2002. p. 264-75.

12. Hofer BK. The Development of Personal Epistemology: Dimensions, Disciplinary Differences and Instructional Practices. Michigan: University of Michigan; 1997.

13. DeBacker TK, Crowson HM, Beesley AD, Thoma SJ, Hestevold NL. The challenge of measuring epistemic beliefs: An analysis of three self-report instruments. J Exp Educ 2008;76:281-312.

14. Buehl MM, Alexander A. Motivation and performance difference in students' domain specific epistemological belief profiles. Am Educ Res J 2005;42:697-726.

15. Ismail H, Hassan A, Muhamad MM, Wan Ali WZ, Konting MM. Epistemological belief and learning approcahes of students in highed institutions of learning in Malaysia. Int J Instr 2013;6:139-50.

16. Muis KR, Bendixen LD, Haerle FC. Domain generality and domain specificity in personal epistemology research. Educ Psychol Rev 2006;18:3-54.

17. Brownlee J, Purdie N, Boulton-Lewis G. Changing epistemological beliefs in preservice teacher education students. Teach Higher Educ 2001;6:247-68.

18. King PM, Kitchener BA. Reflective judgement: Theory and research on the development of espistemic assumptions through adulthood. Educ Psychol 2004;39:5-18.

19. Palmer B, Marra RM. Individual domain specific epistemologies: Implications for educational practice. In: Khine MS, editor. Knowing, Knowledge and Beliefs Epistemological Studies Across Diverse Cultures. Germany: Springer; 2008. p. 325-50.

20. Chan K. Epistemological beliefs, learning, and teaching: The Hong Kong cultural context. In: Khine MS, editor. Knowing, Knowledge and Beliefs. Netherlands: Springer; 2008. p. 257-72.

21. Zhu C, Valcke M, Schellens T. The relationship between epistemological beliefs, learning conceptions and approaches to study: A cross cultural structural model? Asia Pac J Educ 2008;28:411-23.

22. Hofer BK, Pintrich PR. The development of epistemological theories: Beliefs about knowledge and knowing and their relation to learning. Rev Educ Res 1997;67:88-140. 
23. Moser P. The Oxford Handbook of Epistemology. Oxford, UK: Oxford University Press; 2005.

24. Chan K, Elliott RG. Epistemological beliefs across cultures: Critique and analysis of beliefs structures studies. Educ Psychol 2004;24:123-42.

25. Fox R. Training for uncertainty. In: Merton RK, Reader G, Kendall P, editors. The Student Physician. Cambridge, MA: Havard University Press; 1957.
26. Taylor D, Miflin B. Problem-based learning: Where are we now? Med Teach 2008;30:742-63.

27. Labasky SM. A Study of the Relationships Among Student Nurse Epistemology, Critical Thinking, and Clinical Decision Making. Salt Lake City: University of Utah; 2004.

28. Knight LV, Mattick K. 'When I first came here, I thought medicine was black and white': Making sense of medical students' ways of knowing. Soc Sci Med 2006;63:1084-96. 